\title{
Worldwide Sustainability Hotspots in Potato Cultivation. 1. Identification and Mapping
}

\author{
A. J. Haverkort ; F. J. de Ruijter ; F. K. van Evert* ; J. G. Conijn ; B. Rutgers
}

A. J. Haverkort • F. J. de Ruijter · F. K. van Evert $\left(^{*}\right) \cdot$ J. G. Conijn · B. Rutgers

Plant Research International, Wageningen University and Research Centre, Droevendaalsesteeg 1,

Wageningen, The Netherlands

e-mail: frits.vanevert@wur.nl

\author{
A. J. Haverkort \\ Faculty of Natural and Agricultural Science, Department of Plant Production and Soil Science, University \\ of Pretoria, Private bag X20, Hatfield, Pretoria 0028, South Africa \\ e-mail: a.j.haverkort@wur.nl
}

\begin{abstract}
Potato and its derivatives increasingly become globally traded products. Commercial companies more and more want to quantify the environmental footprints such as the efficiency of the use of land and water, greenhouse gas emissions, and the risks of eutrophication and contamination of the environment with pesticides. From various sources, global maps with grid cells of circa 8,600 ha (near the equator) were drawn representing potatoharvested area, potato fresh tuber yield (land use efficiency), slopes (risks of erosion), precipi-tation deficit (risks of depletion of fresh water resources through irrigation), and average daily maximum temperature throughout the season (risks of occurrence of pest epidemics and emission of pesticides). Hotspots for erosion are the slopes of the mountains in the Andes, African Rift, Southern China and volcanic areas in southern China, and the island countries in Southeast Asia. Fresh water availability may become limited in the East of North America, northern India, and China. Risks of insects are increased in continental hot summer climates and short spring crops with high temperatures towards harvest. Late blight is a threat in all humid areas such as maritime Europe, equatorial tropical highlands, and the humid western Pacific Ring. The examples discussed in this paper can be elaborated for more soil and weather-related factors such as acidity and salinity and heat waves or torrential rains. Sustainable long-term and long-range sourcing is deliberated as well as repercussions of trends such as globalization and climate change; the latter being relative favorable for the root and tuber crop potato compared to grain crops.
\end{abstract}


Keyword Biocide use - Carbon footprint - Depletion of water reserves · Erosion risk · Impact on biodiversity · Indicators · Land use efficiency · Nitrogen surplus · Sustainability · Yield

\section{Introduction}

Potatoes originate from the Andean region where the crop has been grown for over 7,000 years as a staple food crop. Studies (Spooner et al. 2010) show that their specific origin is in present-day southern Peru. Since the introduction of the crop to Europe in the sixteenth century and its worldwide distribution, potatoes have become the fourth largest food crop following wheat, rice, and maize (Spooner et al. 2010). Globally, circa 20 million hectares are grown producing more than 300 million tons annually. The importance of potato as a dietary staple varies based on location and has changed over time. It is an important crop in Europe, especially in Eastern, Central, and North Western Europe where there is the highest per capita production. Southern and eastern Asia have shown the most rapid expansion over the past few decades. China is now the largest potato-producing country in the world (Hijmans and Spooner 2001).

Food production in modern farming uses considerable amounts of resources to produce edible crops. However, cultivation practices can be modified in order to decrease environmental burdens while still meeting the demands for food. To preferably avoid or at least reduce the environmental impacts of food production, it is necessary to assess the environmental impact of the entire food supply chain. Potato may serve as a staple food fresh boiled, as salad, mashed or fried, as a snack food such as crisps or extruded products, or as a source of industrial raw material, e.g., in the paper industry.

Depending on factors such as geographic location, precipitation, day length, solar intensity, and proximity to coasts, local growing conditions and input needs can vary widely. Therefore, applicability of hotspots and improvement opportunities can also vary depending on local growing conditions. For example, while the replenishment of groundwater used by irrigation (Lutaladio et al. 2009) is greatly desired, depending on the growing location, irrigation may not be an important activity. Potato is a coolcondition crop where production must occur in seasons that are both "heat free" and "frost free." At latitudes of $50^{\circ} \mathrm{N}$, frost-free conditions occur in 6 months, approximately between April and September, where rainy seasons are common in the parts influenced by the Atlantic Ocean, such as The Netherlands (Haverkort 1989), although with climate change the situation may alter. Therefore, at $50^{\circ} \mathrm{N}$, the soil will often have sufficient moisture without the aid of irrigation. However, further south near the equator (e.g., $20^{\circ} \mathrm{N}$ ), potatoes can be grown year-round in either lowland or highland depending on the time of the year. However, precipitation is relatively low year-round, and water is often pumped from aquifers for crops such as wheat and vegetable production (Haverkort 1989). Here, an improvement opportunity regarding irrigation can benefit greatly to any farmer wanting to grow potatoes or any other crops provided that water is easily and economically available.

There are several potato-specific hotspots when compared to, e.g., cereals. To cultivate potatoes, the soil needs to be tilled and lifted at several occasions: at plowing, 
planting, hilling, and at harvest. This requires much energy, but most importantly, makes the crop vulnerable to erosion of a resource: the soil in which it is grown. Potato also requires relatively much nitrogen fertilizer - or nitrogen from manurewith risks of nitrogen leaching under irrigation or surplus rain. Potato is relatively sensitive to drought and therefore it responds very well to irrigation, which is a major threat to its sustainability when grown in areas where water reserves reach depletion. The crop is attacked both by pests (Colorado beetle, aphids, nematodes) and diseases, especially late blight caused by Phytophthora infestans, leading to losses and as such, to reduced efficiency of resource use or-when controlledthey require considerable amounts of biocides. When harvested, potato has two disadvantages compared to cereals: the product contains about $80 \%$ water, hence is perishable and needs therefore cooling and ventilation during storage. Moreover, its transport costs and impact on $\mathrm{CO}_{2}$ emission per kilogram dry matter are high as a fourfold weight of water is moved.

Part of the seed potatoes traditionally are transported over long distances especially from highlands to lowlands and from high latitudes to low latitudes, and maybe considered a globally traded commodity. From initially a local for local product, ware potato - especially as frozen French fries but also fresh potato that serves as raw material for processing into crisps-increasingly becomes a globally traded commodity with products or raw material transported occasionally halfway around the globe. Examples are frozen products from Europe to Australia and Chile and from North America to Japan and fresh crisping potatoes from Germany to the Philippines and from the USA to Indonesia. Following one of many news items that exemplifies this trend:

U.S. exports of frozen potato products to all markets grew $11 \%$ by volume and $16 \%$ by value for the first quarter (July-September) of 2012/13. However, the volume of exports to the United States Potato Board (USPB) target markets increased $18 \%$, while declining $7 \%$ to the rest of the world. Notable increases were seen in the Philippines 76\%, Indonesia 37, Japan 23, Mexico 43, South Korea 50 and Malaysia 26\%. U.S. market share increased in the Philippines from 53 to $79 \%$, in Japan from 75 to $79 \%$ and in Malaysia from 55 to $57 \%$. It is important to note exports during this period were greatly impacted by prices established from the 2011 harvest when the EU and other suppliers had an abundance of product, but the U.S. was tight on product and high on price. However, in many of the USPB target markets where the USPB programs, including the "Why Buy U.S." program, were being implemented, overall demand increased and the U.S. was able to increase exports and maintain or expand market share. (Potato Grower 2012).

The objectives of this paper are to contribute to the development of a method that allows a quick scan of worldwide sustainability hotspots in potato cultivation. This gives insight in which areas of the world potato production is more favorableregarding specific sustainability indicator values - than other areas. Procurement of potato from globally available sources and its products may take this into account when sourcing raw material or finished products. It may guide companies to reduce footprints of land, water, $\mathrm{CO}_{2}$, risks of eutrophication, and risks of contamination of the environment with biocides. 


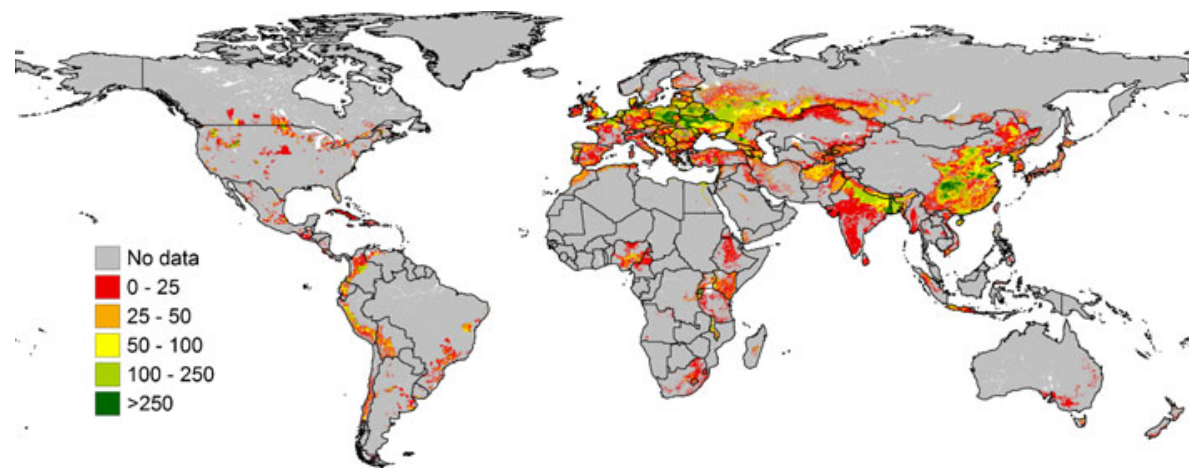

Fig. 1 Harvested areas of potatoes around the year 2000 (ha per grid cell; Monfreda et al. 2008)

\section{Materials and Methods}

To detect and describe potato sustainability hotspots, we made use of maps of the world. Figures 1 (potato area) and 2 (potato yield, land use efficiency) were taken from Monfreda et al. (2008) who mapped harvested areas and yields around the year 2000 of 175 crops according to grouping and naming by FAO with a grid size of 5-min square, about 8,600 ha at the equator. The data were from 206 countries and from the smallest political units obtainable. When more than one crop per year is grown, the area is counted more than once.

The other maps such as those of slopes and precipitation deficit only show such aspects of the grid cells where potatoes were harvested (overlays). Slopes (Fig. 3) have been derived from the Global Terrain Slope and Aspect Data (Fischer et al. 2008), based on 3-arc-second data ( $\sim 90 \mathrm{~m}$ at the equator), and aggregated to 5-min latitude/ longitude grid cells with slope gradients classified into eight classes. We used $2 \%$ slope as threshold since at this level, risk of run-off erosion is considerable.

To identify areas with a precipitation deficit or surplus during the growing season, first, the growing season was defined. The monthly global $0.5^{\circ}$ gridded land surface climate dataset (TS 3.1) for the period 1901-2009, developed at the Climatic Research Unit (CRU) (Jones and Harris 2008), is used and values have been downscaled to the 5min grid. Total precipitation and potential evapotranspiration (PET) per month were

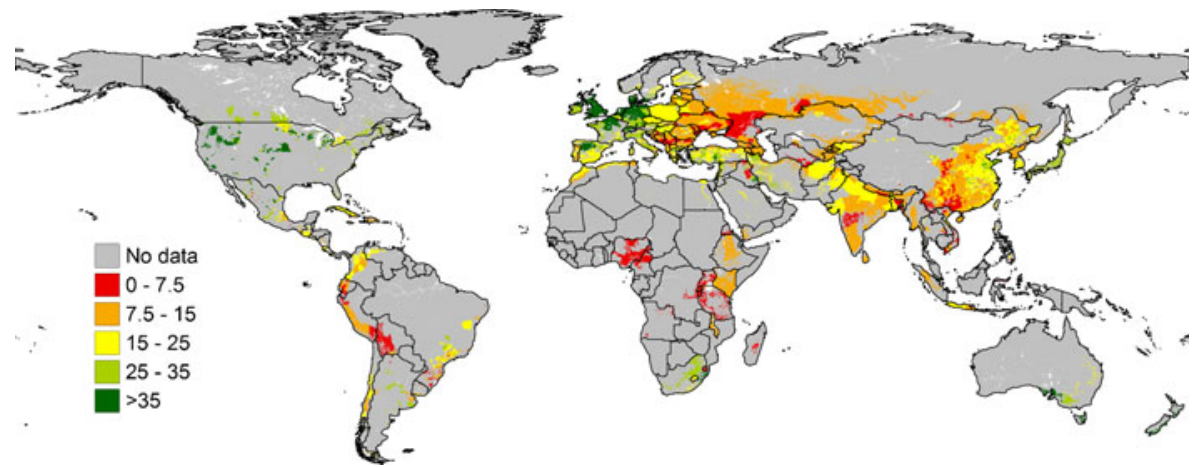

Fig. 2 Fresh tuber yield of potatoes around the year 2000 of grid cells with harvested area $>0$ (tons ha $^{-1}$ harvest $^{-1}$; Monfreda et al. 2008) 


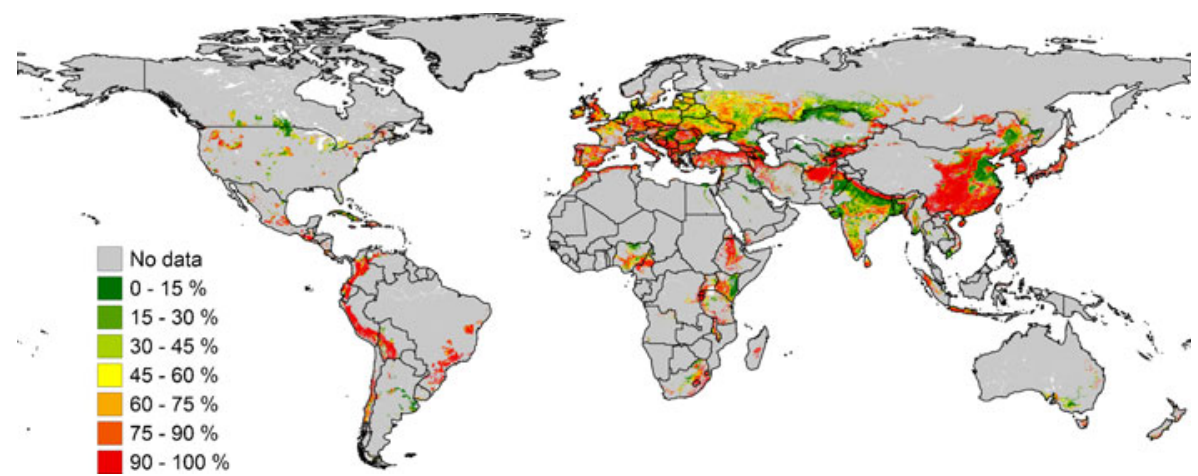

Fig. 3 Occurrence of slopes over $2 \%$ in potato growing areas. The $\%$ in the legend indicates the proportion of the area in a grid cell with slopes over $2 \%$ (Fischer et al. 2008)

averaged over the years 1981-2009. Average accumulated precipitation surplus during a potato-growth period was calculated as precipitation minus PET. A proportionate part of precipitation and PET was taken when the potato growth period covered only part of a month. The potato growth period was estimated according to Verhagen et al. (2000) and defined by the temperature window that is suited for potato growth, and crop growth duration based on temperature sum. For the temperature window, a lower threshold of average day temperature of $5{ }^{\circ} \mathrm{C}$ and an upper threshold of average day temperature of $24{ }^{\circ} \mathrm{C}$ was used. Average day temperatures were obtained by linear interpolation of monthly mean temperature data from the CRU TS 3.1 datasets (Jones and Harris 2008), averaged over the years 1981-2009. The temperature sum required to complete a growing cycle varies between 1,250 and $2,000{ }^{\circ} \mathrm{C}$ days, with a base temperature of $2{ }^{\circ} \mathrm{C}$. For grid cells where multiple potato crops per year can be grown, the period with the highest precipitation surplus was chosen. The same data base and seasonality were used to calculate the average daily maximum temperature during the growing season. We used a cylindrical projection.

\section{Results}

Figure 1 shows harvested potato area (hectares) per grid cell. The about 20 million hectares of potato are grown on all continents. The highest concentrations are found in the temperate zone of the northern hemisphere where the crop is grown in summer during the frost-free period. In tropical regions, the crop is restricted to the highlands of the Andes, the African Rif, and volcanic mountains of West Africa and Southeast Asia. In the subtropics, the crop is grown as a winter crop during the heat-free period such as in the Mediterranean region, North India, and southern China. The crop here is planted in November and harvested around March 1. The rest of the year, it is too hot to grow potatoes and warm enough to grow two rice crops. Regions with over 10\% of the area cropped with potato are rare (some parts of Eastern Europe and Yunnan in China) but there are many areas with over $2.5 \%$ cropped with potato such as in many parts of Central and Eastern Europe and in the Indo-Gangetic plain and parts of central and southern China (data not shown). Potato is absent in tropical lowlands as temperatures are too high for tuber growth, but the crop appears in all other eco-regions and as such 


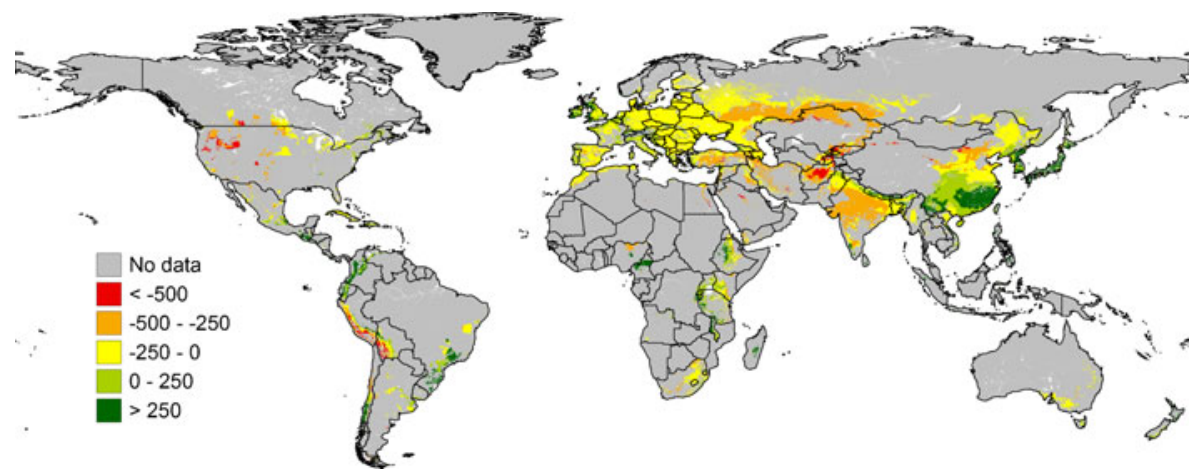

Fig. 4 Average accumulated precipitation surplus (precipitation minus potential evapotranspiration) during potato growth period (mm cycle ${ }^{-1}$; weather data from Jones and Harris 2008)

is one of the global crops with a most diverse distribution pattern. Only the areas with potato occurring in a grid cell are used for the overlays of the Figs. 2, 3, 4, and 5.

The higher the yield, the higher the land use efficiency; so, low yields are indicative of a land use sustainability issue. The global annual production of 300 million tons is the product of area (Fig. 1) and yield (Fig. 2). Lower yields are synonymous to a lower land use efficiency meaning more land is needed to fulfill the demand for potato. Figure 2 shows the highest land use efficiencies ( $>25 \mathrm{t}$ per hectare) to be situated in North America and North-West Europe. Here, high input levels in rain-fed and irrigated cropping systems combined with long frost-free periods with long days and high solar input assure such yields. Both production and processing in these regions are highly mechanized leading to a globally relative suitable competitive situation. A cropping season here may exceed 150 growing days from planting to harvest with mid-season photoperiod exceeding $15 \mathrm{~h}$ per day. A yellow color in Fig. 2 is indicative of a relatively low yield of around $20 \mathrm{t}$ which are found in, e.g., central and eastern Europe, India, and China. Yields may be limited by a short growing season due to a long winter such as in the northern part of North America, Central and Eastern Europe, and North China, Korea, and Japan (Hokkaido).

Winter crops in the subtropics are also restricted in time to some 100 days growing season due to the length of the heat-free period but also because of limited availability

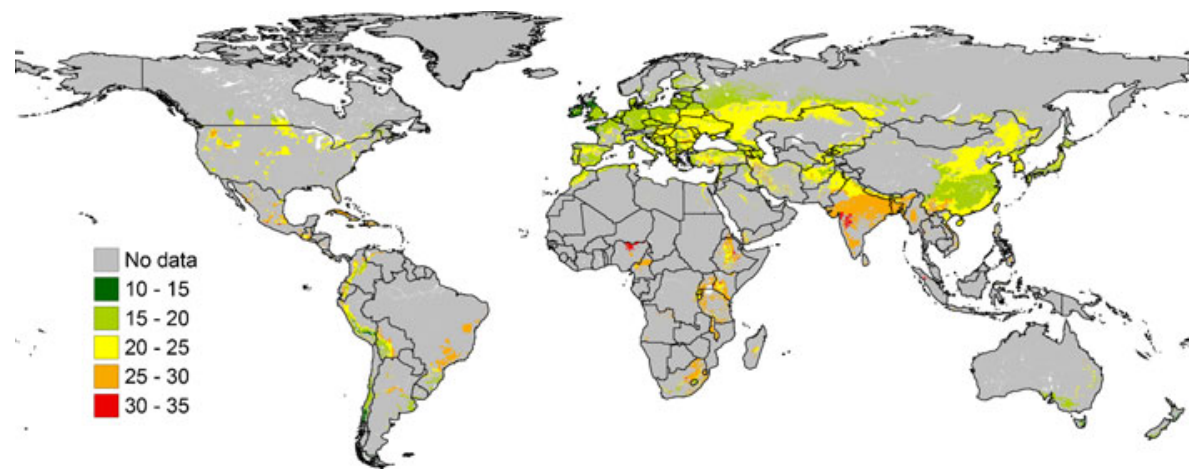

Fig. 5 Average daily maximum temperature during the growth period of potato $\left({ }^{\circ} \mathrm{C}\right.$ per grid cell; weather data from Jones and Harris 2008) 
of solar radiation due to short days and low solar elevation above the horizon. The Indo-Gangetic plains, southern China and Japan and Egypt are examples thereof. Some "red colored" tropical highlands (Fig. 2) have yields as low as about 5-10 t per hectare per cycle. This is mainly due to limited use of resources such as good quality seed, fertilizers, and crop protectants. Here, often, more than one potato crop per season is grown per year, which to some extent, compensates the low production per cycle.

The potato originates from the high Andes areas with steep slopes where the crop is grown on man-made terraces. Since its global spread in the seventeenth and eighteenth centuries, it especially was distributed to temperate Northern American and Northern European production regions, and the plains of India and the north of China that have the lowest proportion of land with slopes over 2\% (Fig. 3). Figure 3 shows seven different levels from dark green representing regions where less than $15 \%$ of the land has slopes of $2 \%$ to dark red with $90 \%$ of the land has slopes over $2 \%$. The mountainous regions of the Andes, Southern Europe, the Near East, East Africa, the Himalayas, and Central and Southern China, obviously have the highest concentration of steep slopes. Often, when slopes become too steep, farmers create terraces such as in Peru and China; the map would then tend to overestimate the potential for erosion. The areas with the lowest occurrence of slopes are the plains of the eastern part of North America (Idaho, Washington Basin), alluvial plains in western Europe, Central and eastern Europe, the Indo-Gangetic plain, and the flat areas of northern China (Heilongjiang and Inner Mongolia). When comparing Figs. 2 and 3, often, a higher proportion of slopes coincide with lower yields. Apparently, flat areas allow mechanization (Jasinski et al. 2005) and higher technology levels and or have better climates.

Where rainfall during the growing season exceeds evapotranspiration, a crop experiences a precipitation surplus and theoretically on average does not need supplemental irrigation. Figure 4 shows such regions in the mountains of East Africa, the Himalayas, but also in flatter areas such as in southern parts of South America, Korea, and Japan. Most of the potato-growing regions have some precipitation deficit such as the northern European plains, Central China, and the Eastern part of North America. Regions with up to 500-mm precipitation deficit are where the crop is grown during a dry winter such as in the Indo-Gangetic plains but also inland summer cropping systems in Turkey, Eastern Europe, and North Eastern China (Ningxia). More severe deficits with over $500 \mathrm{~mm}$ are found in desert conditions such as in the western parts of North America and the Central Andes.

The average daily maximum temperature during the growing season is shown in Fig. 5. Obviously, the closer to the equator, the higher the temperatures are during the growing season with Canada experiencing lower temperatures than the USA. The higher elevation of the Andes Mountains compared to the African mountains is reflected in the lower average daily temperature during the growing season in the Andes. Continental climates have short but warm summers explaining why the temperatures are higher in the low plains in China's North than in the Southern highlands. The maritime climate in western Europe assures low temperatures due to the proximity of the Atlantic Ocean but further inland in Central and Eastern Europe and Asia, the temperatures are higher during the summer growing season at similar latitudes. Higher temperatures during the growing season lead to higher development rates of insects (Van der Waals et al. 2013) such as aphids, Colorado beetle, white flies, psyllids, and tuber moths and increased numbers of multiplications of free-living nematodes leading 
to either increased crop losses or increased costs of control and emissions related to the use of pesticides. Higher temperatures during growth show where it is more difficult to grow seed potatoes as they may suffer more from aphid-transmitted viruses. Moreover, as a consequence of higher temperatures, the dry matter concentration of the tubers decreases (Haverkort and Harris 1987) which requires more transport per unit dry matter and increased (energy) costs for processing into French fries and crisps.

Finally we correlated yield to slope, precipitation surplus and average maximum temperature during the growing season (Tmax); this yielded the following equations:

Potato yield $=-0.010(\%$ of gridcell area with slope $>2 \%)+16.75, n=349566, R^{2}=0.0012$

Potato yield $=0.00042$ (precipitation surplus) $+16.48, \quad n=321163 R^{2}=0.0001$

Potato yield $=-0.555($ average Tmax in growing period $)+28.43, n=321163 R^{2}=0.0355$

As expected, yields are negatively correlated to slope and high temperatures and positively correlated to rainfall. The low $R^{2}$ values-although the number of comparisons $(n)$ is high-are indicative of the weak degree of explanation showing that yields depend on many factors and that each of the three factors studied only marginally influence yield at the worldwide level.

\section{Discussion}

The approach chosen is mapping some relevant hotspots - not exhaustive as we especially wanted to demonstrate the approach that can be extended-and to discuss their relevance for the current situation and implications of continued trends in consumption, trade, and climate change. In the accompanying paper (Van Evert et al. 2013), the specific use of such basic and processed information is made to discuss in-depth how global consortia such as the Sustainability Consortium may make use of hotspot mapping in general and how thresholds of specific sustainability values may be established for such issues. In this first paper, we discuss the land footprint (where are potatoes grown with which intensity), the risk of erosion (higher slopes), excess or lack of water during the growing season (water footprint), and the average daily maximum temperature during the growing season as it influences tuber quality and risks of insect pest damage. These are just illustrations of our approach and are not exhaustive. Other factors we could have taken are the frequency of heat waves, the extent to which rainfall is erratic or the sandiness of the soil for example. In the second paper (Van Evert et al. 2013), we discuss areas with improvement opportunities and illustrate it with nitrogen fertilizer surpluses, risks of late blight caused by $P$. infestans, overlap of potato production areas with areas which are rich in biodiversity, and how much $\mathrm{CO}_{2}$ is emitted to produce $1 \mathrm{t}$ of potato.

Mapping of environmental sustainability hotspots as carried out in the current study may serve some purpose but needs fine-tuning as there may be pitfalls. In regions with a high land foot print (low yields) there may be growers that serve the global markets with high-yielding crops. Even in regions with a high proportion of sloping land, 
possibly potato may be grown on the most flat land available leaving the rest for perennial crops. Most areas where the crop is irrigated have renewable water resources from rivers that drain mountains or where the water level is restored during winter. There are, however, potato production areas where levels of natural recharge of local aquifers are so low that groundwater levels gradually fall such as in Gujarat, India (Colombia Water Center 2013). Even regions with relatively high temperatures on average may have land at higher elevation with lower temperatures within the almost $55 \times 55-\mathrm{km}^{2}$ size of the grid (near the equator) from the CRU weather database.

This implies that "ground truthing" is needed when assessing if potato can be sourced in a sustainable manner: taking local environmental conditions into consideration thereby specifically paying attention to the environmental aspect that has a red color in the map. To evaluate this and to remediate a hotspot locally, the approach expressing performance in terms of genotype, environment, and management may be helpful.

The performance $(P)$ of the potato crop - its yield and quality, or the amount of finished product per unit area-is a result of, or is determined by, the crop type and variety (genotype $G$ ) that is grown, the environment $(E)$ in which the crop is grown, and by the crop management $(M)$ (e.g., Asseng and Turner 2007).

Therefore, $P=G \times E \times M$.

Zooming in a pixel, the current performance of the crop may be determined at harvest. It is the observed crop fresh tuber matter production graded into various quality grades such as fodder (e.g., smaller than $35 \mathrm{~mm}$ ), fresh market $(35-55 \mathrm{~mm}$ ), and French fries grades (e.g., over $55 \mathrm{~mm}$ ). Dry matter and reducing sugar concentrations are crucial for processing as is the proportion of the tubers suffering from biotic and abiotic defects as they all influence recovery. All these characteristics are quantitative indicators of performance. The most important contribution of the $P$ of performance to improving sustainability of potato is a good description of the specifications (desired size, shape, dry matter, and sugar concentrations) as it determines the recovery (kilogram finished product per ton raw tuber material). Processing companies can draw global maps indicating where not only yields are highest but also where the highest recovery is expected, so rather, maps of kilogram French fries per hectare than yields per se.

Of the three factors leading to performance, genotype $(G)$ is the most important one as it determines where and when (environment) the crop is grown, and how it should be treated (management). Genotypes that have a "length of the growth cycle that best matches the available (heat- and frost-free) growing season" will have the highest yields in a given environment. This is the most effective contribution of a genotype to sustainability, next to contributing to the specifications of the factories that process potato and resistance to (a)biotic stresses that help to bridge the gap between actual and attainable yields. Regarding the abiotic factors discussed in this paper, varieties exist or are being developed that increasingly are adapted to marginalizing conditions such as drought, high temperatures, and results of erosion. Ex-ante assessment may indicate whether varieties from elsewhere may deal with the adverse condition better than local varieties and thus reduce the impact of the hotspot.

Regarding the environment there are many more factors that can be analyzed beside the few that serve as an example in our study. Among these, for example, are soil characteristics such as sandiness, $\mathrm{pH}$, soil organic matter concentration, nutrient availability, sodicity and stoniness, and climatic aspects as represented by long-term weather 
data such as maximum and minimum temperature and solar radiation. Moreover, hazards such as night frost or heat waves may drastically impact resource use, and thereby sustainability. Resource utilization is also reduced when biotic factors such as the presence of pests and diseases reduce yield or quality. An example of this is given in the accompanying paper (Van Evert et al. 2013) on late blight.

Besides influencing genotype and environment by the grower to improve performance and thus doing so diminish the ecological footprints, crop management is the third factor. Hotspots can be partly remediated by management of soil fertility (through manure and fertilizers, lime), soil water content (through irrigation) and pest and disease control. The accompanying paper (Van Evert et al. 2013) addresses some of these issues.

Making use of hotspot maps, as shown here, is beneficial in situations where fresh or processed potatoes are sourced by potato-deficient countries such as the Middle East and Southeast Asia for fresh market or processing purposes or when potato products are sourced such as frozen French fries or starch. The local vulnerability of the environment and the impact of potato production on the area where sourced from, can be taken into account. This, in addition to the impact of transport on the $\mathrm{CO}_{2}$ footprint of potato. Haverkort et al. (2013), Franke et al. (2013) and Van der Waals et al. (2013) investigated the effect of atmospheric $\mathrm{CO}_{2}$ increase and climate change (including changes in average temperature and precipitation) on yields, water use, adaptation measures, and pests and diseases in a time series from 1960 to 2050. The modeling exercises were carried out for rainy and dry winter crops and rainy and dry summer crops, representing the four main potato cropping systems that are also described here: Mediterranean winters, Monsoon climate winters, northern temperate climate summers, and southern temperate highland summers. Yield increases between 2010 and 2050 due to atmospheric $\mathrm{CO}_{2}$ increase $(+30 \%$ yield $)$ and lengthening of the growing season $(+20 \%$ yield) totaling some $50 \%$ are calculated for the rainy summer crops and lower in dry winter crops $(+10 \%)$ due to higher temperatures that reduce the length of the wintercropping season. Water use efficiency in most systems will improve between $10 \%$ and $40 \%$ over this period. The potato crop benefits more from climate change than wheat and rice. When establishing potato-processing plants or future sourcing schemes, this prospect could be taken into account, besides the information that is obtained from sustainability hotspot maps.

Acknowledgments This research was financed by the Netherlands Ministry of Economic Affairs within the framework of the "Kennisbasis I: Global Food Security: Scarcity and Transition" and "Kennisbasis V: Value Chains" strategic research programs.

\section{References}

Asseng S, Turner NC (2007) Modelling genotype x environment x management interactions to improve yield, water use efficiency and grain protein in wheat. In: Spiertz JJJ, Struik PC, van Laar HH (eds) Scale and complexity in plant systems research: gene-plant-crop relations. Springer, New York, pp 93-104

Colombia Water Center (2013) http://water.colobia.edu/research-projects/gujarat-india/. Accessed 10 Oct 2013 Fischer G, Nachtergaele F, Prieler S, van Velthuizen HT, Verelst L, Wiberg D (2008) Global Agro-ecological Zones Assessment for Agriculture (GAEZ 2008). IIASA, Laxenburg, Austria and FAO, Rome, Italy

Franke AC, Haverkort AJ, Steyn JM (2013) Climate change and potato production in contrasting South African agro-ecosystems 2. Assessing risks and opportunities of adaptation strategies. Potato Res 56:51-66 
Haverkort AJ (1989) Ecology of potato cropping systems in relation to altitude and latitude. Agric Syst 32: 251-272

Haverkort AJ, Harris PM (1987) A model for potato growth and yield under tropical highland conditions. Agric For Meteorol 39:271-282

Haverkort AJ, Franke AC, Engelbrecht FA, Steyn JM (2013) Climate change and potato production in contrasting South African agro-ecosystems. 1. Effects on land and water use efficiencies. Potato Res 56:31-50

Hijmans RJ, Spooner DM (2001) Geographic distribution of wild potato species. Am J Bot 88(11):2101-2112

Jasinski E, Morton D, DeFries R, Shimabukuro Y, Anderson L, Hansen M (2005) Physical landscape correlates of the expansion of mechanized agriculture in Mato Grosso, Brazil. Earth Interact 9:1-18

Jones P, Harris I (2008) University of East Anglia Climate Research Unit (CRU), CRU Time Series (TS) High resolution gridded datasets [Internet]. NCAS British Atmospheric Data Centre. Available from: http:// badc.nerc.ac.uk/view/badc.nerc.ac.uk_ATOM_dataent_1256223773328276. Accessed 4 Dec 2012.

Lutaladio N, Ortiz O, Haverkort A, Caldiz D (2009) Sustainable potato production; guidelines for developing countries. Food and Agriculture organization of the United Nations. ISBN 978-92-5-106409-2

Monfreda C, Ramankutty N, Foley JA (2008) Farming the planet: 2. Geographic distribution of crop areas, yields, physiological types, and net primary production in the year 2000. Global Biogeochem Cycles 22: GB1022. doi:10.1029/2007GB002947

Potato Grower (2012) http://www.potatogrower.com/potato-industry-news/display.cfm? ID=2276. Accessed 27 Dec 2012

Spooner DM, Gavrilenko T, Jansky SH, Ovchinnikova A, Krylova E, Knapp S, Simon R (2010) Ecogeography of ploidy variation in cultivated potato (Solanum sect. Petota). Am J Bot 97(12):20492060. doi:10.3732/ajb.1000277

Van der Waals EJ, Kruger K, Franke AC, Haverkort AJ, Steyn JM (2013) Climate change and potato production in contrasting South African Agro-Ecosystems. 3. Effects on relative development rates of selected pathogens and pests. Potato Res 56:67-84

Van Evert FK, de Ruijter FJ, Conijn JG, Rutgers B, Haverkort AJ (2013) Global sustainability hotspots in potato cultivation. 2. Areas with improvement opportunities. Potato Research. doi:10.1007/s11540-0139248-7.

Verhagen A, Grashoff C, Uithol PWJ, Haverkort AJ (2000) Agro-ecological zoning of potato. Wageningen, Plant Research International, Report 7 